every city system of schools, and quotes Germany's example, followed by Austria after Sadowa. Credit is given also to the Germans for leading the way in ventilating school-rooms scientifically. In 1858 Pettenkofer's method of testing the impurity of the air in a room came into use, and a description is here given of a different simple apparatus for the same purpose. The conclusion is drawn that organic matter in "bad air" is more frequently the dangerous part of it than superabundant carbonic acid. England, while at the higher schools formally ignoring this branch of education, nevertheless really recognises it in the games which make themselves of so much importance at the Universities and the great schools that feed them. Physical training was despised and repressed by the monks of old, who founded these schools, and taught that the body was at enmity with the soul, and that the more the former was weakened the more the latter was strengthened and purified; and if with Mr. Galton we regret that all the softening elements of human nature were eliminated by monastic celibacy, we may also console ourselves that, but for it, many injured constitutions must have been handed down as the result of such tenets. Schoolmasters now know that the difficulties of teaching are immensely increased by any physical disorder, and that an absolute incapacity to learn follows some bodily ailments. Imperceptibly increasing from the sleepiness which follows upon a good dinner comes the dulness caused by the bad air of ill-ventilated rooms. There is a long and full paper on this latter subject prepared for independent publication by the Bureau of Education, of great value but too general in its teaching to be epitomised here.

Another cause of what to thoughtless teachers seems irritating stupidity is partial deafness. Interesting observations upon the varieties of this infirmity among school children have been made by Dr. Sexton, of New York. Careful estimates show that only 5 per cent. of the entire population of the United States have normal hearing. Ten per cent. of pupils have such defective hearing as to make special placing and such like care for them in schools necessary. If a teacher has not made himself fully acquainted with the amount of this deafness, a very slightly deaf pupil will either be liable to be sent to the deaf-and-dumb school, or he will leave the ordinary school in disgust at the teacher's harsh and unfair reprimands. Prof. Graham Bell's audiometer is found to answer well in the work of classifying defective hearers. On behalf of the deaf-mute school Mr. Dobyns boasted that theirs was the only universal language: when he met an educated deaf-mute not only from America but from France, Germany, England, or Japan, he could hold communication with him.

From an examination of about forty thousand cases, a Committee on the subject draws the important conclusion that, while very few pupils indeed are short-sighted when they first enter school, "the number afflicted, and the degree or intensity of the disease, gradually but surely increase through the entire school life, from class to class, from year to year, until, when the Co!leges and Universities are reached, in many cases more than half the students are near-sighted." This Committee strongly recommends increased use of the black-board and less use of books. This practice has been found to reduce the amount of myopia to one-half. A Report of a second Committee on the causes of it recommends that the head should not be bent forward too much over a desk. Near-sightedness has increased in Alsace since German letters have been used there. There is a special danger of its being brought on at about fifteen years old, the age of puberty.

While these deficiencies are to be found in so large a proportion of children, however, Mr. Jepsen, teacher of music in New Haven, limits the number of children who have really what is called "no ear" for music to less than 4 per cent., and he urges that it may profitably be taught in a thoroughly scientific way to be familiarly read. The Commissioner has felt the importance of this matter so much that through the co-operation of a Music 'Teachers' Association the heavily burdened Bureau has been already able to draw up and issue a Circular of Information on the study of music in public schools. It is remarked that singing seems to be despised as a school pursuit in the United States, and to be less popular and more neglected than in England. It is taught that mental culture comes chiefly through the eye; moral culture through the ear and voice. Sounds can be taught to children much more easily than numbers. To read music, again, is as great a superiority over singing it by ear as being able to read is better than having learnt a few pieces by heart.

Bearing upon the same question of classifying children according to their powers is a short paper read by Mr. E. Chadwick, of educational celebrity in England, who urges the economy of dividing the bright children from the dull, so as to educate them in less time $-\mathrm{a}$ most desirable arrangement for all parties, where it is practicable.

Two papers, one of them also by Mr. Chadwick, take up the subject of rewards and punishments. Mr. Chadwick protests against the use of the stick, while Prof. Barbour urges first the needlessness, and then the danger, of giving prizes, which may breed a sordid character, supply unworthy and therefore unstable motives. They are, he thinks, of no value at all to any but a very few in each class. But in each case it is necessary to supply a motive which the very young can fully appreciate; some terror must be held over the young transgressor's head, and so long as terror is the motive power, the stick is as fair as any other, with the advantage that each culprit is an example to all who see his discomfort, and the influence upon them is nearly equal to that of being caned themselves. The refined torture of solitary confinement, which is considered less degrading, has not this advantage. In like manner, everything in this world is done for a prize, even if that prize be a "high calling," and school-boys require some outward and visible sign of successful labour, books, marks, or class-places. The grosser methods of marking it might well be dropped as the children get older. But rewards we all strive for, and it is untrue that no higher and wider valuation of knowledge replaces the ambition to take home a prize which first led to a laborious pursuit of it.

\section{W. ODELL.}

\section{ABSTRACT OF THE RESULTS OF THE IN- VESTIGATION OF THE CHARLESTON EARTHQUAKE. ${ }^{1}$ \\ II.}

ET us suppose an elastic wave to originate at a point C (Fig. I) situated at the depth $q$, below the surface. Let the intensity of the shock (amount of energy per unit of wave-front) at the distance unity from C, be denoted by $a$. Since the intensity is inversely proportional to the square of the distance, the intensity at the epicentrum would be $q^{2}$. Take any other point on the surface of the earth at the distance $x$ from the epicentre, and connect it with $\mathrm{C}$ by the line $\mathrm{C} x=r$. The intensity at any such point will obviously be equal to $\frac{a}{r^{2}}$. If we denote the intensity by $y$, we shall then have the equation-

$$
y=\frac{a}{r^{2}}=\frac{a}{q^{2}+x^{2}} .
$$

This equation expresses a curve which will serve as a

I Paper read before the National Academy of Sciences at Washington. on April $x 9,1887$, by C. E. Dutton, U.S.A., and Everett Hayden, U.S.N., U.S. 
graphic representation of the way in which the surface intensity varies along a line radiating from the epicentre.

The first noteworthy feature of this curve is the contrast between the rapidity with which the intensity diminishes near the epicentre and the slowness with which it diminishes at remote distances. Thus, at a distance from the epicentre equal to the depth of the focus, the intensity has fallen one-half; at twice this distance it has fallen to one-fifth ; and at three times the distance to one-tenth of

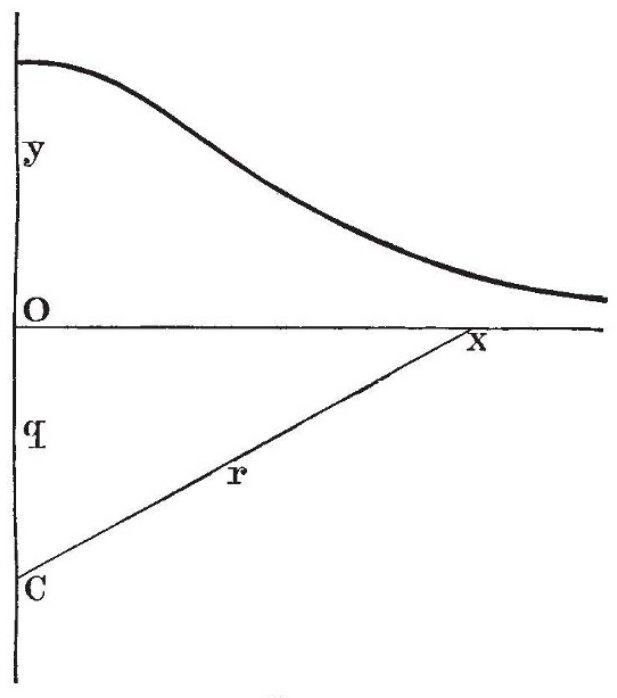

FIG. I.

the intensity at the epicentre. This suggests at once the possibility of making an approximate estimate of the depth of the focus, based upon the rate at which the intensity of the shock at the surface diminishes in the neighbourhood of the epicentre. If we were able to construct upon any arbitrary scale whatever a series of isoseismal curves around the central parts of the earthquake with an approach to accuracy, this depth would follow at once from the relations of these isoseismals to each other. In the case of a very powerful earthquake in

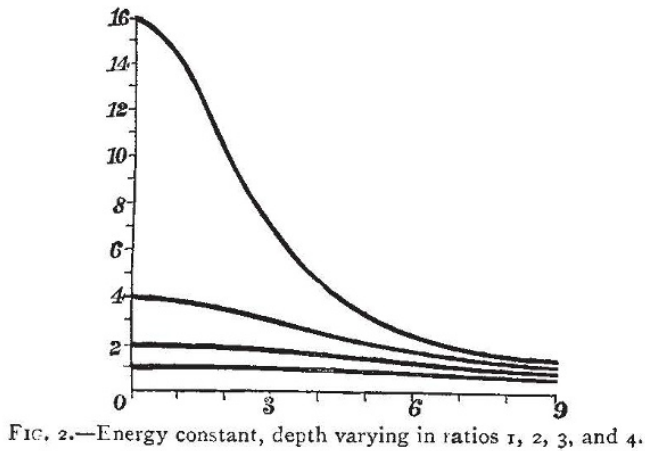

a region which is so flat and uniform in its features as the vicinity of Charleston, this can be done with a rough approach to accuracy.

To appreciate more fully the validity of this mode of reasoning, let us take a series of these intensity curves and vary the values of the constants. And first let us suppose the total energy of the shock measured by the constant, $a$, remains the same, while the depth of the focus varies. The fir st series of curves (Fig. 2) will enable us to make a comparison of the effect of two or more shocks of the same total energy but originating at different depths. The intensity at the epicentre being inversely proportional to the square of the depth, the shallower shock would be much more energetic than the deeper one; while at a great distance from the epicentre the two would be approximately equal in their effects. The rate of diminution of intensity would be correspondingly varied, and we might commit large errors in estimating these ratios on the ground, while the error of the depth deduced for the focus would be less than our errors of estimate. In short, the method is not sensitive to small or moderate errors of observation.

The second series of curves (Fig. 3) is conditioned upon the assumption that the depth remains constant while the

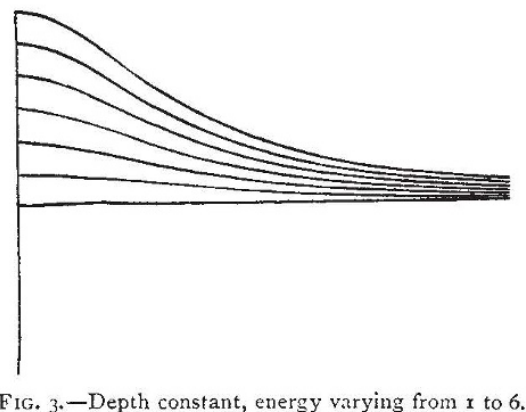

energy of the shock varies. In these curves, the ordinates corresponding to any abscissa are proportional to each other in a simple ratio. In the first series they are proportional to each other in a duplicate ratio.

The third series (Fig. 4) represents the effect of varying both the energy and the depth in such a way that the intensity at the epicentre is constant.

It will appear, therefore, that every shock must have some characteristic intensity curve, depending upon the total energy and the depth below the surface. The intensity at any point along the surface will therefore depend upon these two quantities: energy and depth. It still remains to find some means of discriminating whether the intensity at any point is due to a more energetic

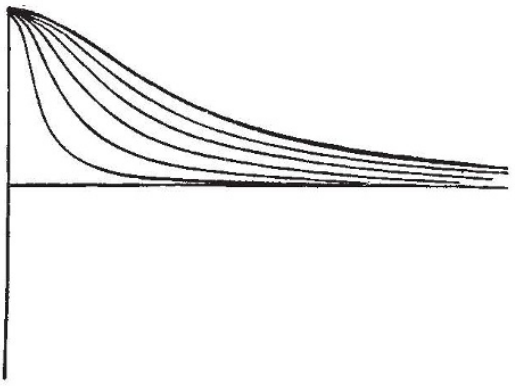

FIG. 4-Lepth and energy both varying, but with constant intensity at the ep:centrum.

shock deeply seated, or to a less energetic one nearer the surface. The criterion is soon given.

It is obvious that in any shock there is some point at some particular distance from the epicentre at which the rate of diminution of surface intensity has a maximum value. As we leave the epicentre and proceed outwards in any direction, the intensity diminishes at first more and more rapidly, but further on diminishes less and less rapidly. We wish to find the point at which the rate of decline changes from an increasing to a decreasing rate. In the curve this point is represented at the point of inflexion where the curve ceases to be concave towards the earth; and begins to be convex towards it. To find the co-ordinates of this point we differentiate the equation 
of the curve twice, and equate the value of the second differential coefficient to zero, and deduce the corresponding value of the abscissa $x$ -

$$
\frac{d^{2} y}{d x^{2}}=\frac{8 a x^{2}-2 a\left(q^{2}+x^{2}\right)}{\left(q^{2}+x^{2}\right)^{3}}=0 ;
$$

which equation is satisfied when

whence

$$
8 a x^{n}=2 a\left(q+x^{2}\right)
$$

$$
\pm x=\frac{q}{\sqrt{\prime}} .
$$

In this value of $x$, it is seen that the constant, $a$, has disappeared, and the abscissa of the point of inflexion is therefore independent of the energy of the shock, and dependent upon the depth alone. The meaning of this is that the distance from the epicentre to the point where the rate of decline of the intensity is greatest is simply proportional to the depth of the focus, and is the same whether the energy be greater or less. This property of the intensity curves makes us independent of any absolute standard of measurement of the intensity, and all that we require is to find with reasonable approximation the points where the intensity falls off most rapidly. The depth of the focus follows at once.

The determination of the epicentral tract is chiefly the work of Mr. Earle Sloan, of Charleston, a young civil engineer who immediately after the disaster made an extensive series of observations. In the brief time at his disposal he accumulated a surprisingly large amount of detailed information, and in searching for it exercised a discrimination and sagacity which would have been highly creditable to the most experienced and learned observer. It is to be regretted that his business engagements prevented him from continuing the work. As it is, he has located with considerable precision the epicentral tract, and has furnished data which show well the variation of intensity along several lines radiating from it.

The summary obtained from the examination of $\mathrm{Mr}$. Sloan's data is as follows:-The tract which includes the most forcible action of the earthquake is an elliptical area about twenty-six miles in length, and with a maximum width of about eighteen miles. The major axis of this area is not a straight line, but a curve which is concave towards Charleston, and is situated from fourteen to sixteen miles west and north-west of that city. Along this line there are three points each of which has all the characters of an epicentrum, determined by as many distinct shocks, each having a focus of its own.

Much of the most powerful shock centres in the northernmost focus, though the other two were of sufficient energy to have occasioned great havoc if either of them had occurred alone. The southernmost was also considerably more energetic than the middle one. The distance between the northern and southern epicentres was about twelve miles. Within this tract, except near the edges of it, the motion was most conspicuously of subsultory character, $i e$. motion in which the vertical component predominated over the horizontal. The marginal portions of this area, where the character of the movement changes, and where the intensity falls off most rapidly, seem to be very well indicated. The positions where the intensity most rapidly declines may be confidently located with an error not exceeding one or two miles on both sides of the epicentres. The South Carolina Railroad crosses the tract in a straight line very near the most forcible seismic vertical. The first point where the intensity falls off with greatest rapidity is near the ninth mile-post, measuring from the railway depot in Charleston, and so well marked upon the ground are the indications of this change, that it seems very improbable that this point is more than a mile distant either way from the precise point we seek to locate. Passing north-westward through Summerville to the opposite side of the tract, we find the corresponding point of most rapid decline in the vicinity of the twentythird mile-post. This gives us a base-line with which to measure the depth of the focus of the principal shock. The computed depth is twelve miles, with a probable error of one or two miles. The computed depths of the other foci are about the same, but the probable errors are somewhat larger.

In speaking of a focal point of a shock, it must be understood as referring to the centre of all the forces, considered with reference both to amount and direction, which constitute a great seismic impulse. The presumption is that this impulse originates in a large subterranean tract, of which this ideal focus is merely the central point, or nearly so. The form of the subterranean tract may be anything; and, within limits, may have its three dimensions, length, breadth, and thickness, of any magnitude, and bearing any ratios to each other. The form and dimensions of it we cannot of course determine, though it may be possible to obtain some notion of its most general features if the data are sufficient.

This method of computing the depth of a seismic focus is here proposed for the first time. The method employed by Mallet, which consists in finding the angle of emergence of a wave front from the earth by studying the configuration of cracks in buildings is believed to be valueless by nearly all seismologists. There is no definite angle of emergence of the nature he contemplates dis. closed at the surface. Certainly in Charleston there was nothing of the kind to be found. The method employed by Seebach is sound in theory, but it requires such extreme accuracy of time determinations that very small errors of time give very large errors in the result. Our own method consists of finding two points on opposite sides of the seismic vertical, at which the changes in seismic action along a given line are most strongly marked. These points ought to be indicated in powerful earthquakes with a fair approach to precision, and the probable errors of determination should not usually exceed one or two tenths of the distance between the two points. The feebler the shock, however, the less is the degree of precision to be expected. Whatever may be the errors in the estimate of this distance, the resulting error in the computed depth is smaller than the error of observation in the ratio of the square root of three to two. How much the estimate may be vitiated by want of homogeneity in the superficial strata we have no means of determining, but we do not believe that it would be so affected to any great extent in such a region as South Carolina. Being independent of any absolute measures either of the surface intensity or of the total energy of the shock, the greatest difficulty of all is at once eliminated. Our opinion of this method is that it is incapable alike of very great precision and of very great errors

Probably the first thought occurring to anyone examining this method will be that the determination of the two required points would be liable to very large errors. But if he will examine the varying values of the ordinates of the curve corresponding to varying values of the abscissæ, and of the depth, we think he will be satisfied that the limits within which each of the two points of inflexion must fall cannot be wide apart, and that an error in the determination of the base-line greater than twotenths of its estimated length would, in such a country as Carolina, be very improbable. It will appear that the relations of these variables are such as to restrict the locus within which the desired points are to be found to a very narrow annulus around the epicentrum. We think the method will greatly improve on acquaintance.

We have endeavoured to apply our method of computing the depth of the focus to other earthquakes, but have found difficulty in obtaining anything more than very general results, such as the following:-The depth of the 
Charleston earthquake was relatively great, and we find reason for believing that, among those great earthquakes of the last 150 years of whose effects we possess any considerable knowledge, none have originated from a much greater depth, and few from a depth so great. Our reasoning is this:-Very few earthquakes have been felt at a distance from the origin so great as 1000 miles. But the greatest distance at which the tremors are felt is the best measure of the total energy of the shock. On the other hand, the intensity of the Charleston earthquake in the epicentral tract was relatively low in comparison with other great earthquakes. If, then, any shock is more intense at the epicentre, without extending to a greater distance than that of the Charleston earthquake, it is certain that its focus was nearer the surface. This is true of the vast majority of recent earthquakes which have been sufficiently investigated. It is suggested that all estimates of the depth of foci much exceeding that of the Charleston earthquake are in need of re-examination.

The city of Charieston is situated from eight to ten miles outside of the area of maximum intensity, and did not experience its most destructive power. Following the law which we have laid down, the intensity of the shock at Charleston was only three-tenths what it must have been at the epicentrum and about one-third the intensity at Summerville. The diagram showing the long intensity curve stretching from Charleston to a point

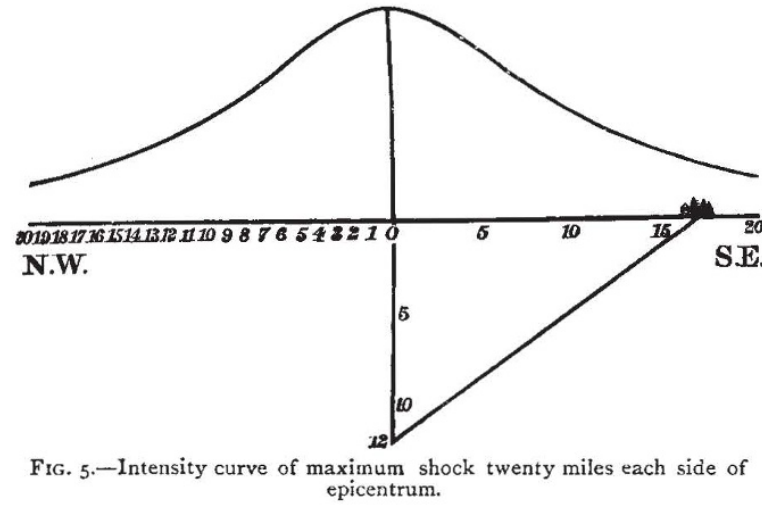

forty miles north-west of it will illustrate the position of the city with reference to the varying force of the shock.

$\mathrm{Had}$ the seismic centre been ten miles nearer to Charleston, the calamity would have been incomparably greater than it was, and the loss of life would probably have been appalling. $\Lambda$ nother circumstance greatly broke the force of the shocks. All the coastal region of the Carolinas consists of a series of clays and quicksands, which have been penetrated by artesian borings to a depth of 2000 feet, and which are believed to have a much greater thickness. These beds of loose material no doubt absorbed and extinguished a considerable portion of the energy of the shocks. We have already remarked that a wave passing from firmer and more elastic material into material less firm and elastic produces at first an increased amplitude of wave-motion, which is liable to be more destructive or injurious to buildings. But if the mass of less consistent strata be very great, the reverse result is produced by reason of the rapid extinction of the energy in passing through a considerable length or thickness of very imperfectly elastic material. We cannot but think that Charleston owes in some measure its escape from a still greater calamity to the quicksands beneath the city.

Another aspect of the same fact, if such it be, is found 100 miles west and north-west of Charleston. Here the loosely-aggregated sediments of Tertiary and Cretaceous age which cover the Carolina coastal plain have thinned out, and the crystalline rocks appear at the surface, thinly covered with soil and alluvium. All along the junction of these loose strata and superficial material with the metamorphics the intensity of the shocks was conspicuously greater than to the eastward and southward. The loose covering of these firm rocks is just thick enough to give full effect to the increased, amplitude of vibration which occurs when the wave passes from very solid and elastic rocks to those which are less so.

We have also endeavoured to reach some trustworthy estimate of the amplitude of movement at the surface, but the results are meagre and far from satisfactory. The "amplitude of the earth particle" in any earthquake is a question of great practical importance, and it is much to be regretted that no better facilities for determining it can be obtained. There were, however, many occurrences at Charleston bearing upon this question, which are extremely difficult to explain upon any valuation of the amplitude less than Io inches to a foot. Such amplitudes, however, were most probably limited to spots here and there, while in other spots it was probably much less. That within a small area the amplitude of movement in the surface soil varies between very wide limits seems to be a practically certain conclusion from the observations. In Charleston it appears to have been greatest in the "made ground," where ravines and sloughs were filled up in the early years of the city's history. The structures on higher ground, though severely shaken, did not suffer so much injury.

With regard to the time data from which the speed of propagation must be computed, we are not yet in a position to give final results, but can only state how the problem stands at present. The time reports have been placed in the hands of Profs. Rockwood and Newcomb, with the request that they would scrutinize and discuss them. But neither has been able to finish as yet the task he has so courteously undertaken. Probably the greatest difficulty in the way of determining the speed of propagation arises from the ill-defined character of the disturbance at considerable distances from the origin and from the very considerable duration of it. Wherever a time observation seems to be well authenticated, there still remains in most cases the difficulty of deciding to what particular phase of the earthquake the record refers. And this difficulty is a very serious one. At Summerville the first shock came almost like an explosion. Before people had time to think, they were pitched about like ten-pins. At Charleston there was a perceptible interval estimated at from five to eight seconds from the first note of warning to the maximum of the great shock. At Savannah (ninety miles distant), the interval from the beginning to the first maximum was considerably longerprobably ten to twelve seconds; at Augusta (II5 miles), the interval was still greater. And, generally speaking, the greater the distance the more the phenomena were "long drawn out." The duration of the earthquake at Charleston will probably never be known with accuracy. But the general testimony ranges between fifty and ninety seconds. At Washington (450 miles), Prof. Newcomb with his watch in his hand observed a duration of perceptible tremors, with two maxima, lasting about five and a half minutes. Prof. Carpmael's magnetographs recorded the disturbance, and he interprets their photographic traces as showing a duration of about four minutes. Mr. G. W. Holstein, of Belvidere, New Jersey, gives five minutes very nearly as the observed duration. From other localities come well-attested observations showing durations of several minutes, though few of these pretend to give the whole time with any accuracy. This progressive lengthening of the shocks is a well-marked feature of the testimony. The explanation suggests itself at once. The elastic modulus of compression being greater than that of distortion, the speed of the normal waves is the greater while the waves of distortion lag behind. 
It is obvious that the phase which it is desired to observe should be the arrival of the first impulses. But the great duration of the tremors has left much doubt on this point. Stopped clocks were plentiful all over the country, but at what phase of the earthquake did they stop? So great, indeed, are the uncertainties on this point that the observations of intelligent men, with watches in their hands measuring a part of the shock and estimating the beginning, are in most cases to be preferred to stopped clocks, even though we know with certainty that the clocks had been accurate to the second. It matters little how we twist and turn the time data: the smallest estimate we can put upon the speed of propagation must prove to be a great surprise to seismologists.

The time at Charleston of the occurrence of the main shock has been fixed at 9 h. I $5 \mathrm{~m}$. IOs. p.m., $75^{\text {th }}$ meridian or Eastern standard time. ${ }^{1}$ (All times in this paper, unless otherwise specified, are reduced to that meridian.). The uncertainty does not exceed ten seconds. The beginning of the first tremors at Charleston was from six to eight seconds earlier. The time at Summerville was probably less than four seconds earlier than Charleston. For all localities within 200 miles the time observations are of little value. So swiftly did the waves travel that a small error in the time record gives a very large uncertainty in the resulting speed.

The nearest point which yields a valuable record is Wytheville, Va. (286 miles). ${ }^{2}$ Mr. Howard Shriver was sitting at a transit instrument, waiting for the passage of a star, and at once noted the time at 9h. $52 \mathrm{~m}$. $37 \mathrm{~s}$. (reduced to $75^{\text {th }}$ meridian), giving a speed of about 3.3 miles (5300 metres) per second. There is some slight uncertainty about the precise phase of the shock corresponding to the observation.

The Signal Service Observer at Chattanooga (332 miles) gives only the nearest minute for the principal shock at $9 \mathrm{~h}$. $53 \mathrm{~m}$., corresponding to a speed of $3^{\circ} \mathrm{O} 2$ miles per second, or 4860 metres.

The best observation in our possession is that of Prof. Simon Newcomb himself, at Washington (450 miles), who gives the time of the beginning of the shock at $9 \mathrm{~h} .53 \mathrm{~m}$. 20s., with an uncertainty not greatly exceeding ten seconds. The resulting speed is 3.46 miles per second, or 5570 metres.

From Baltimore (486 miles), Mr. Richard Randolph, C.E., reports a very intelligent and carefully verified

I For European readers it seems necessary to refer briefly to the American "standard time" system, which will assist them in estimating the character of these time records. Throughout the Atlantic States all clocks designed for accurate time-keeping are set daily to the time of the 75 th meridian west of Greenwich. In the Mississippi Valley they are similarly set to the time of the goth meridian; in the Rocky Mountains to that of the 105th, and on the Pacific coast $t$ ' ' the roth meridian. They are called respectively, Eastern, Central, Mountain, and Pacific time, and the differences are exact hours. At some convenient hour every day the wires of every railroad and telegraph company in the country are put into circuit with the clock of some astronomical observatory (or with some standard clock controlled by an astronomical observatory (or with some standard clock controlled by an astronomical clock), and time signals are sent to every railway station and
telegraph office. The station agents, or telegraph operators, of these companies are held responsible that these signals are received, and that their pantes are held responsible that these signals are received, and that their
clocks are regulated by them daily. A failure to do so is a breach of discipline. The greatest purveyor of accurate standard time is the Western Union Telegraph Company, which furnishes it at a small charge to some railways, to telephone exchanges, to town and city offices, to hotels, to private corporations; in short, to anybody who wants it. For the Eastern and Southern States it takes its time by a special wire from the National Observatory at Washington. The system is essentially perfect, whereby clocks can be set once each day to exact standard time in every railway station an telegraph office in the country. And at every such station and office it is the duty of somebody to see that it is carried out. How accurately this is done is another matter. It depends upon the discipline of the companies and the habits of individuals, in which there are no doubt varying degrees of precision. The clocks supplied are always good ones, and ought not to have daily error of over four or five seconds. But the best clock ever made will not kee good time unless properly managed. The demand for extremely accurat time throughout the greater part of the United States is enormous, and this acts as a constraint upon the companies and their employés to carry out the system with precision. This same demand has led to the organization of private companies in large towns and cities who receive time from the Western Union Telegraph Company and purvey it to private houses, hotels, merchants, workshops, \&e.

2 The distances have been measured somewhat hastily with a scale upon the War Department map of the United States, taking the greater epicentrum seventeen miles north-west of Charleston as the origin. observation of $9 \mathrm{~h} .53 \mathrm{~m}$. 20s. as the beginning of the shock-exactly Prof. Newcomb's time for Washington, giving a speed of 374 miles, or 6000 metres, per second.

At Atlantic City, N.J. (552 miles), a large pendulum clock in the Fothergill House stopped at 9 h. $54 \mathrm{~m}$., very nearly. If this may be taken to be the beginning of the shock, the speed would be 3.26 miles per second, or 5250 metres.

George Wolf Holstein, Belvidere, N.J. (622 miles), gives $9 \mathrm{~h} .54 \mathrm{~m}$. for the beginning of the shock and $9 \mathrm{~h} .59 \mathrm{~m}$. for the end, and compared his watch next morning with the time of the Pennsylvania Railroad. The gradual and uncertain character of the beginning and end would not admit of precise determination to seconds. The speed, taking $9 \mathrm{~h} .54 \mathrm{~m}$. for the beginning, would be 3.66 miles, or 5900 metres.

From New York City (645 miles) and its suburban towns and cities come many reports, all of which give either $9 \mathrm{~h} .54 \mathrm{~m}$. or $9 \mathrm{~h} .55 \mathrm{~m}$. as the nearest minutes. If we take, as a mean, 9h. 54m. 25s. at New York and Brooklyn for the beginning of the shock, the speed would be 3.31 miles, or 5330 metres.

At distances greater than 600 miles the difficulty of associating the time records with particular phases of the shocks becomes very great. In most cases the motion was the swaying movement, with only faint tremors of the rapid kind, and those who felt them were slow in recognizing their character. Readers must form their own opinions as to the degree of approximation to the time of the earliest movements from the following records. We give them only as we received them, without attempting any discussion.

J. O. Jacot, watchmaker and jeweller, at Stockbridge, Mass. (772 miles), was sitting by his regulator clock; distinctly recognized the nature of the movement, and noted the time as $9 \mathrm{~h} .56 \mathrm{~m}$. The phase of the shock is uncertain.

At Albany, N.Y. (7خे2 miles), Mr. J. M. Clarke, of the New York State Museum of Natural History, heard the mortar falling down the chimney, and the creaking and straining of the building. As soon as he appreciated the character of the disturbance he noted the time by his watch as 9 h. $56 \mathrm{~m} .30 \mathrm{~s}$. He did not ascertain the error of his watch. In the same city, Dr. Willis G. Tucker says he instantly looked at his watch, and after comparing it next morning with the time of the Dudley Observatory, and making correction of the error, gave gh $55 \mathrm{~m}$., very nearly, with an error probably not exceeding twenty seconds.

From Fonda, N.Y. (780 miles), Francis L. Yates reports 9h. $55 \mathrm{~m}$. (no particulars).

At Ithaca, N.Y. (695 miles), the regulator clock on the wall of the railway depot stopped at $9 \mathrm{~h}$. $55 \mathrm{~m}$. "exactly."

At Gowanda, N.Y. (666 miles), where the shocks were faintly felt, W. R. Smallwood, watchmaker and jeweller, noted the end of the perceptible shocks at $9 \mathrm{~h} .55 \mathrm{~m}$. $30 \mathrm{os}$. by his regulator clock.

At Toronto ( 753 miles), the earthquake was recorded automatically upon the magnetographic traces in the observatory of Prof. Chas. Carpmael, Superintendent of the Meteorological Service of Canada. In his letter of September I 4 he says :- "I may state that at 9 h. $55 \mathrm{~m}$. p.m. all our magnetic needles were set in motion by earth tremors. The vibrations of the magnets were continued for about four minutes. I would say that from later and more careful measurements from our magnetic curves I make the time of the earth tremor at Toronto to be 9h. 54m. 50s. p.m., standard; this time, I should say, would not be astray more than a few seconds." As this record was automatic, and gave not only the time but the phases, it has been thoroughly investigated by Profs. Newcomb and Carpmael, assisted by Mr. C. A. Schott, of the U.S. Coast Survey. The final result of this reexamination is to change Prof. Carpmael's computation 
to $9 \mathrm{~h} .56 \mathrm{~m} .18 \mathrm{~s}$. for the beginning of the tremors, with a probable error of fully one minute. This large probable error is due to the very small scale upon which the magnetograph records time intervals (one-tenth of a milli metre corresponding to twenty seconds), and to want of sharpness in the photographed traces. This time gives 2*66 miles per second, or 4250 metres, with a probable error of one or two tenths of the amount.

The clock in the Western Union Telegraph Office at Pittsburgh ( 523 miles) was stopped at 9 h. $54 \mathrm{~m}$.

From Cincinnati and suburban towns (500 miles) come many reports. In this city local mean time is largely used, owing to the fact that it is nearly midway between the 75 th and goth meridians, where the only inconvenience of standard time is at a maximum. The correction to the $75^{\text {th }}$ meridian is $+37 \mathrm{~m}$. 40s. The Western Union Telegraph Office gives $9 \mathrm{~h}$. $54 \mathrm{~m}$. The Times-Star newspaper gives, from the clock in its own office, $9 \mathrm{~h} .16 \mathrm{~m}$. "exactly" (9h. 53m. 40s. standard); at the Commercial Gazette office, 9 h. $17 \mathrm{~m} .45 \mathrm{~s}$. local, 9 h. $55 \mathrm{~m}$. $25 \mathrm{~s}$. standard (probably noted after the shocks were over). At the fire tower, after the principal shock, $9 \mathrm{~h}, 16 \mathrm{~m}$. $17 \mathrm{~s}$. was noted; clock error, twenty-three seconds slow, giving $9 \mathrm{~h} .54 \mathrm{~m} .20$ s. standard. Two other observers, noting by watches, give $9 \mathrm{~h} .16 \mathrm{~m}$. ; and one notes an advanced stage of the shocks at $9 \mathrm{~h}$. I $7 \mathrm{~m}$., but give no means of estimating their errors. At Covington, Ky., across the Ohio River, I. J. Evans, watchmaker and jeweller, reports his regulator clock stop ped at $9 \mathrm{~h}$. $\mathrm{I} 7 \mathrm{~m}$. 20s., Cincinnati local mean time. Phase of shock unknown.

From Crawfordsville, Ind. (622 miles), E. C. Simpson, C.E., reports through Prof. J. M. Coulter, of Wabash College: "Suddenly felt my chair move, jumped up and said, 'We are having an earthquake'; at once pulling out my watch I found it was $8 \mathrm{~h}$. $54 \mathrm{~m}$. p.m. standard time (Central)." Prof. Coulter adds that the watch was exactly with railroad time as shown at the railroad station, and also by the town clock.

From Dyersburg, Tenn. (569 miles), Louis Hughes writes:- "My time-piece was an English patent lever watch of Chas. Taylor and Son, London, which from business necessity I keep closely with railroad time at the station, which receives the time at ro o'clock every morning. The railroad uses Central time. My first thought was that the shaking was caused by the children in the next room; but in the next moment, recognizing the peculiar sensation, I dropped the newspaper and observed the time, which was probably four to six seconds after $8 \mathrm{~h} .54 \mathrm{~m}$., and from that approximated it in even minutes." Speed 3.25 miles, or 5230 metres.

At Memphis, Tenn. ( 590 miles), the Signal Service Observer reports a considerable number of stopped clocks, one at 9 h. $54 \mathrm{~m}$. and the others at $9 \mathrm{~h} .55 \mathrm{~m}$. For some unaccountable reason the seconds were not noted. The phase is unknown.

The foregoing comprise those time reports which seem to justify the presumption that the errors do not exceed one minute. There are others, which are obviously rude approximations, giving exact hours, quarter-hours, or tens of minutes. There are also some which look at first like good observations, but which surely involve some large unexplained error.

As the discussion of the time data is now progressing, no further comment will be offered here beyond the remark that there can be no doubt that the speed of propazation exceeded 3 miles, or 5000 metres, per second. The only questions are how much this speed was exceeded and whether the speed along any given line was constant. As regards the latter question, the data are not yet precise enough to justify an opinion. This matter will be inquired into.

The high rate of propagation will probably prove unexpected to European seismologists. We propose, however, to follow it up with the suggestion that it is about the normal speed with which such waves ought to be expected to travel, and that all determinations of the rate of propagation in any former great earthquakes which are much less than 5000 metres per second (for normal waves at least) are probably erroneous in proportion as they fall short of the Charleston earthquake. Finding as the time reports accumulated that a speed in excess of 5000 metres was indicated, and this presumption having become a conviction, we were led to inquire whether there was not some speed deducible from the theory of wave-motion in an elastic solid to which all great earthquakes ought to approximate.

In a homogeneous and perfectly elastic solid, the rate of propagation is, according to theory, dependent upon two properties of the medium: elasticity and density. There are two coefficients of elasticity in solid bodies, one of which measures their resistance to changes of volume; the other, to changes of form. Absolute experimental determinations of the values of these coefficients have never been made. If, however, we knew the ratios of these coefficients in one substance to the homologous coefficients in any other substance, and if we also knew the rate of propagation in either of them, the rate in the other would be at once deducible. The rate in steel bars has been the subject of much experimentation, and is given by Wertheim, whose researches have been as careful as any, at 16,800 feet per second. But as the waves in a steel bar are essentially waves of distortion, he multiplies this result by $\sqrt{\frac{3}{2}}$ or $\frac{5}{4}$ for the normal wave, giving a speed of 21,000 feet per second. The elastic modulus of steel for engineering purposes is usually taken to be $29,000,000$. The corresponding modulus for such rocks as granite and basalt in a very compact state is about $8,000,000$. If we may assume that these moduli are proportional to the two elasticities of the two substances respectively, we can compute the rate of propagation in rock. This assumption may or may not be true : but we assume it to be so. Let $V_{s}$ be the rate of propagation in steel, and $\mathrm{V}_{r}$ the rate of propagation in rock, and let $e_{s}$ and $e_{r}$ be their true compressional elasticities, and let $\mathrm{D}_{s}$ and $\mathrm{D}_{r}$ be their respective densities. Our assumption is that $29: 8:: e_{s}: e_{r}$ from which we may form the equation -

$$
\frac{\mathrm{V}_{s}}{\mathrm{~V}_{r}}=\sqrt{\frac{e_{s}}{\mathrm{D}_{s}} \times \frac{\mathrm{D}_{r}}{e_{r}}}
$$

Taking the density of steel at $7 \cdot 84$, and of deeply-buried rocks in their most compact state at 2.85 -

$$
\frac{V_{s}}{V_{r}}=\sqrt{\frac{29}{7.84} \times \frac{2.85}{8}}=1.15 \text { nearly. }
$$

Taking the rate of compressional waves in steel to be 6400 metres per second, gives 5570 metres for similar waves in very compact and dense rock. The corresponding rate for waves of distortion would be 4450 metres. These results are so near to those deduced for the Charleston earthquake that they seem to be worthy of consideration.

The experimental measurements of the rate of impulses ob:ained by Milne and Fouqué seem to us inapplicable. The elasticity of the surface soil, we think, is no more to be compared with that of the profound rocks which transmit the great waves of an earthquake than the elasticity of a heap of iron filings is to be compared with that of an indefinitely extended mass of solid steel. The difference is toto calo. But the rate of propagation is a question of elasticity and density chiefly. The effect of temperature we have not considered. Perhaps the most striking experiment ever made with an artificial earthquake was at the Flood Rock explosion at Hell Gate, near New York, where General Abbott found a speed of propagation approaching very closely to that of the Charleston earthquake. 
The question which is undoubtedly of deepest interest in this connexion is whether the Charleston earthquake throws any new light upon the origin of such events. While we are not prepared to say that absolutely nothing will be added to our information on this question, we are forced to admit that we expect very little new light. Hitherto our efforts have been devoted to bringing together the facts and to arranging and comparing them, and we have as yet given but little consideration to this final question. It will, however, shortly engage our attention, and in anticipation of this we prefer to remain silent for the present, fearing that, if we commit ourselves here to any preference for a particular view, we may find ourselves encumbered with a bias arising from the intensely human propensity to defend, through thick and thin, utterances which have once been formally given.

ON A POINT OF BIOLOGICAL INTEREST IN THE FLOWERS OF "PLEUROTHALLIS ORNATUS," RCHB. F.

I N December of last year (I886), in the Orchid-house at Kew, a specimen of Pleurothallis ornatus ' flowered. Not only is this the first time that it has done so at Kew, but I am informed by Mr. Watson, of the Royal Gardens, who drew my attention to it, that hitherto P. ornatus has not been known to flower in captivity.

The flowers of this plant present a most interesting adaptation, whereby to attract insects, of which I propose in this note to give a short account.

The genus Pleurothallis is characterized (generally speaking) by the inconspicuousness of its flowers, which, as a rule, are of a reddish-brown colour. The flowers are either solitary and axillary, or in few-flowered racemes. The outer perianth-whorl (sepals), though never exceeding a few millimetres in length, is several times longer than the inner (petals). The sepals are sub-equal, and the lateral ones slightly connate at the base. The two lateral petals are small and wing-like on either side of the column. The short, superiorly-grooved labellum is always shorter than the petals, and articulates with the column by a narrow flexible neck. Such an arrangement, in consequence of which the labellum is more or less vibratile, and after a touch will oscillate several times, is found in several allied genera, e.g. Restrepia, and especially Bolbophyllum. The genus Pleurothallis is tropical American, and epiphytic.

Pleurothallis crnatus is especially distinguished from other members of the genus in the fact of its sepals possessing an extremely conspicuous fringe of white cirrhi. In no other species of the genus, of which I have been able to find figures or specimens, is anything of the kind seen. ${ }^{2}$. The hair-like structures which form this fringe in $P$. ornatus average about 2 millimetres in length; and when it is remembered that the extreme diameter of an expanded flower does not exceed io millimetres some idea of the conspicuous part played by the fringe is obtained. Figs. I and 2 are respectively front and lateral views of a flower, magnified about five diameters. Each hair it will be seen narrows very much at its proximal end, and is in this way rendered versatile. From the fact of the hairs being air-containing they are excessively light, and moved by every breath of air. The motion of course is an entirely passive one-they are simply swayed to and fro on the hinge formed by this tapering.

In Fig. 3 is represented a microscopic view of one of

I Described by Prof. H. G. Reichenbach in Wittmack's Gartenzeitung, 1882, p. ro5. To him I am indebted for this reference.

2 Except perhaps in Pleurothallis ciliata, which is described and figured by Knowles and Westc tt in "The Floral Album," vol. i. p. 40. Here, however, it is the petals which have a ciliated border. No description is given of the hairs, though the authors mention having examined them microscopically. The figure is a bad one, and barely shows the existence of a the cirrhi detached. It consists simply of a prolongation of one of the epidermal cells at the edge of the sepal-and its lumen is continuous with that of the epidermal cell from which it originates (cf. Fig. 4). In form, the hair resembles that of a flattened club. Its width, throughout most of its extent, averages 0.2 millimetres. But it is flattened in the plane at right angles to this, so that its thickness is only about 0.025 millimetres. Externally the hair has a granular aspect, arising from numerous slight rugosities of its delicate cuticle (cf. Fig. 3). At its proximal end it narrows as it runs into the epidermal cell from which it arose.

In the expanded flower the hairs are air-containing, the protoplasm being entirely collapsed and dried up.

The versatile hairs are inserted along the margin of the sepals at intervals of less than I millimetre. Towards. the attached part of the sepals they become much shorter.

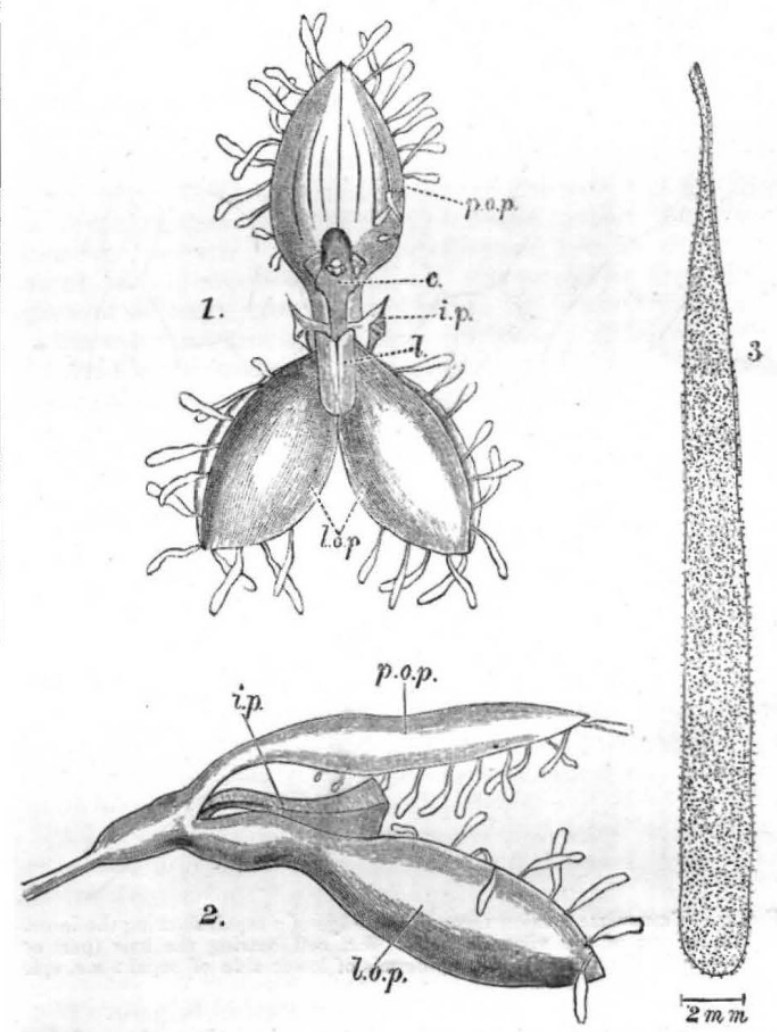

FIG. $1 .-V i e w$ of the flower from in front, $\times 5$ diameters. $c$, colimn: $i$, $p$, petals ; $l$, labellum : l.o.p, lateral sepals ; p.o.p, posterior sepal. FIg. 2.-Lateral view of same flower, $\times 5$ diameters. References as in FIG. 3.-A single isolated vibratile hair, much magnified.

The precise mode of insertion is seen in Fig. 4, which represents a transverse section of the edge of a sepal. The hair is formed from one of a group of small cells (h.c) at the extreme edge of the sepal. In the figure are seen its relations to the parenchyma, and to the upper and lower epidermis (u.e and l.e) of the sepal.

I have been unable to examine buds of the plant, consequently no account can be given of the development of these hairs.

As regards its biological meaning, there can, I conceive, be little doubt but that the fringe serves to attract insects which fertilize the otherwise inconspicuous flowers. The white lustrous appearance of the cirrhi is a consequence of their air-content; and it is as important a factor as their versatility, in successfully rendering the small brown flowers conspicuous to insects. As I have 